\title{
Experimentation in a Research Workshop: A Peer-Learning Approach as a First Step to Scientific Competence
}

\author{
http://dx.doi.org/10.3991/ijep.v3iS3.2748 \\ Philipp Ossenberg ${ }^{1}$ and Thorsten Jungmann ${ }^{2}$ \\ ${ }^{1}$ TU Dortmund University, Dortmund, Germany \\ ${ }^{2}$ FOM Hochschule für Oekomonie \& Management, Essen, Germany
}

\begin{abstract}
Engineers are supposed to be clever innovators and creative problem solvers. First-year engineering students usually do not learn to solve technical problems creatively. They usually do not learn how to innovate. In this paper we describe FLExperiments as a new learning format in a research-based learning environment named FLEx-Forschungswerkstatt (research workshop). FLEx provides student-focused, competence-oriented and research-based learning. Conducting FLExperiments means that students solve small technical problems by experimentation and subsequently document their findings in a scientific report. In this learning process they are assisted by their peers, who act as tutors. FLExperimentation includes the iterative process of experiential learning synchronized with a research process. To demonstrate the idea of FLExperimentation we are giving the example of an experiment from the field of kinetics: the Loop.
\end{abstract}

Index Terms-Engineering Education, Higher Education, Creativity, Experiential Learning, Research-based Learning

\section{INTRODUCTION}

First-year engineering students attend courses in mathematics, physics and mechanics, but most of them will not apply their knowledge in a creative problem-solving situation until they start thinking about their bachelor thesis [1]. Usually, solving technical problems creatively by using mathematical and physical knowledge is not an explicit part of engineering curricula, although the ability to do so is one of the core competencies of engineers. This paper presents a research-based learning format for Engineering Education, which compensates for the mentioned deficiency. Students conduct experiments and apply their knowledge, skills and competencies acquired in mathematics, physics and mechanics. Thus they reflect their theoretical knowledge in the mirror of practical experimentation - engaged in research-based learning. This concept has already been presented at EDCON 2013 in Berlin [2].

\section{Design Methods}

In order to ensure that our students achieve the intended learning outcomes (ILOs), which we will concretize in section IV, the FLExperiements are designed by implementing constructive alignment [3]. The design follows the idea of synchronizing Kolb's Learning Cycle with a research cycle that is typical for engineering research projects $[4,5]$. The didactical concept includes a peerlearning approach.

\section{A. Constructive Alignment}

The design concept Constructive Alignment is based on the alignment of Indented Learning Outcomes, Learning Activity and the Assessment. Designing engineering curricula therefore means to align the assignments in the learning process and the assignments in exam situations with the assignments that emerge from the objective of employability and citizenship (cf. Fig. 1) [6].

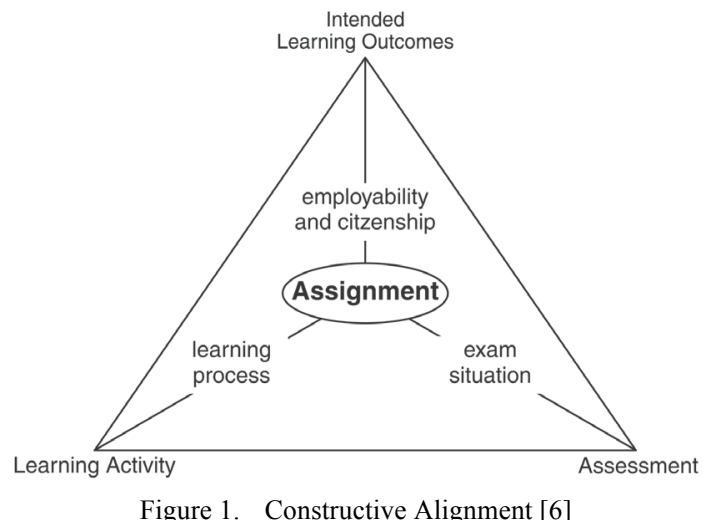

\section{B. Sychrononizing Kolb's Learning Cycle with Jungmann's Research Cycle}

Fig. 2 shows Kolb's Learning Cycle [4] synchronized with a typical research cycle in the field of engineering according to Jungmann [5].

Kolb's concept of experiential learning is a "well accepted (...) efficient pedagogical model of Learning" [7]. Experiential learning was developed using the theory of Lewin, Dewey und Piaget. The learning cycle in the center of fig. 2 closely corresponds with the Model of Action Research and Laboratory Training developed by Kurt Lewin.

Arnegger determines that the learning cycle can start at each position [8]. Normal explanations start with (1.) Concrete Experience. In this part of the learning cycle students irritated by a situation or an experience [9]. This condition is the initial point for the experiential learning process. The second part is (2.) Reflective Observation. In this part students have to reflect their experienced irritation. Reflective Observation is used in part three to develop an (3.) Abstract Conceptualization. The developed concepts will be verified during (4.) Active Experimentation. After these four stages the learning cycle recommences. 


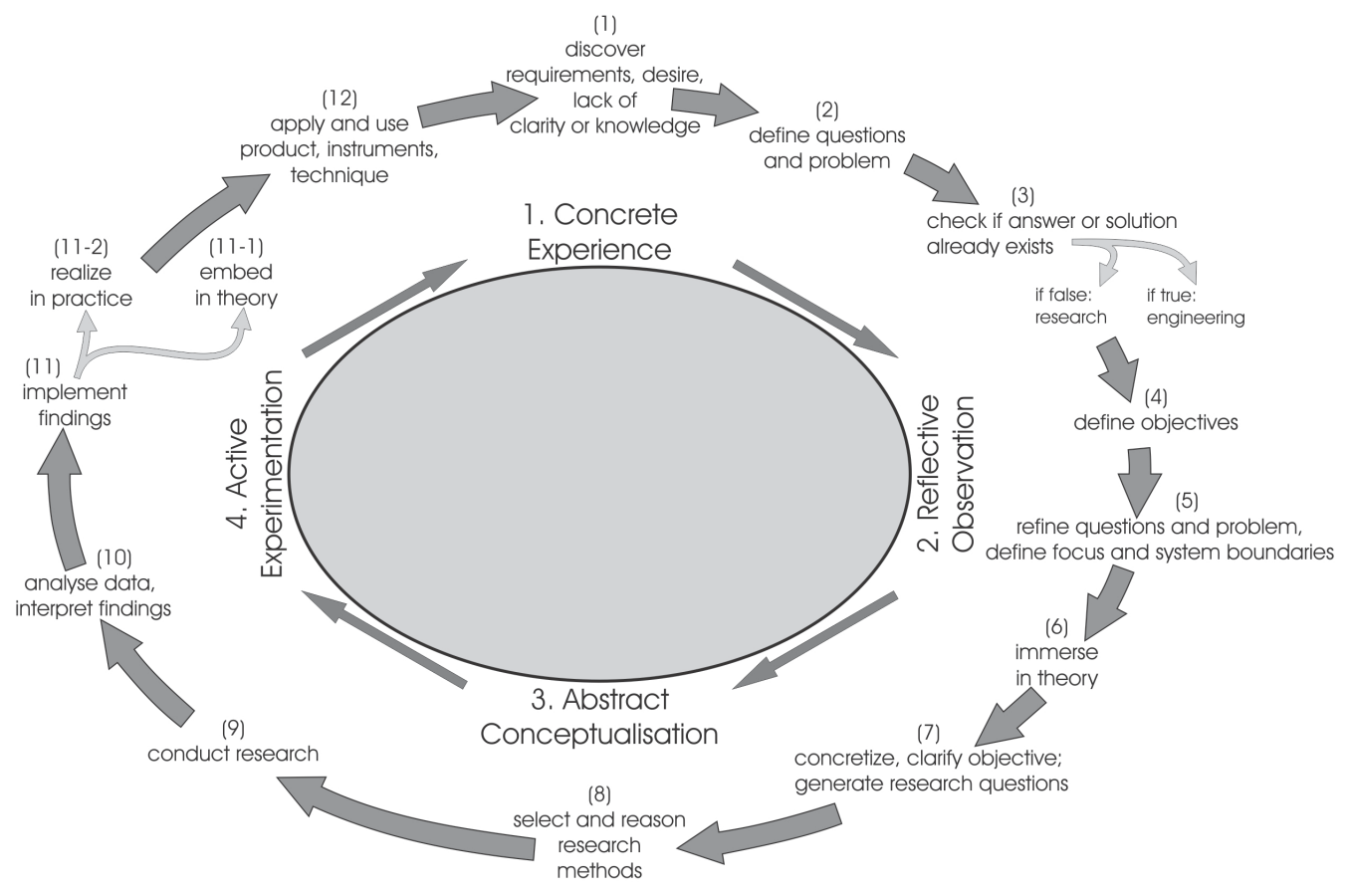

Figure 2. Kolb's Learning Cycle sychronized with Jungmann's Research Cycle [4]

The research cycle shown in fig. 2 was developed by Jungmann [5] to implement research-based learning in Eng- neering Education following Wildt's postulation that the synchronization of learning and research processes needs to be specified for each discipline, as a core step towards research-based learning $[9,10]$.

\section{Peer-learning and Peer-tutoring}

In short terms peer-learning means that "(...) students learn with and from each other (...)" [11]. Boud emphasizes the advantage of peer learning: "The advantage in learning from people we know is that they are, or have been in a similar position to ourselves" [12]. Having the same status and background makes it is easier for students to ask questions and accept feedback than in situations with lecturers or professors.

We assume that “(...) most effective learning environment is one where learning is an active process fully involving the learner, preferably in groups in a supportive and non-threatening environment (...)"'[13] in [14]. Students are fully involved in their learning process if they plan, perform and evaluate experiments that we provide them.

Mahdi states that " $(. .$.$) productive collaborative study$ group sessions are often difficult for students to organise and plan themselves" [14]. Therefore peer-tutors assist our students in organizing and in the learning process itself.

\section{LEARNING ENVIROMENT}

FLEx-Forschungswerkstatt is a room open for students to conduct research on their own projects, learning about the re-search process and make small experiments like the one described in this paper. Students can take advantage of our tutors' assistance in learning, group working and researching. There are also courses offered, in which students enhance their key qualifications. In our research workshop we provide literature, experimentation kits and material that can be used to visualize results (laptops, video projector, whiteboards, flipcharts, pin boards, different cards and pens).

\section{LEARNING FORMAT: FLEXPERIMENT}

In this section we present our developed learning format based on the described design methods. We define the Intended Learning Outcomes, describe the learning activities and the assessment.

\section{A. Defining Intented Learning Outcomes}

Intended Learning Outcomes have been defined based on a global objective for engineering education e.g.: "The overall goal of engineering education is to prepare students to practice engineering and, in particular, to deal with the forces and materials of nature" [15]. "Intended learning outcome" clarifies what the students should be able to perform after teaching that couldn't be performed previously (...)" [3].

- ILO 1: Students acquire skills to successfully perform experiments.

- ILO 2: Students are able to create assumptions, verify them by experimentation and to refine their assumption based on their findings.

- ILO 3: Students are able to write a scientific report.

About ILO 1 Engineers often require data from experiments to design and develop products [15]. The ability to generate knowledge using experiments is a competence that students in engineering education have to learn. Skills and competences in successful experimentation include knowledge about limitations of experimentations itself and the limitations of mathematical and physical models. Reaching ILO 1, students are also able to distinguish between principle errors and faulty assumptions.

About ILO 2 Create, verify and refine assumptions by experimentation requires critical reflection of the procedures before, while and after the experiment, from the given hypothesis till the scientific report. This ILO is more 
concrete than ILO 1. It is also a subset from ILO 1 but an essential one, so it is important to define it more specificly as a separate ILO.

About ILO 3 One of the core competences of engineers working in science is to communicate their research findings to people inside and outside the scientific community. The most important way for communication in science is writing reports and papers. In papers and reports the findings have to be presented in a structured and logical order. Students writing bachelor and master theses are faced with the same requirements. It is therefore essential to develop these competencies as early as possible in engineering education.

These three ILOs are defined as educational objectives for all FLExperiments. Additionally, subject-related ILOs are defined for each experimental set-up, e.g. Students are familiar with the conservation of energy in case of the experiment presented in this paper.

\section{B. A new Learning format}

After defining ILOs we were looking for a learning format that fits our ILOs and has an optimal cost benefit ratio. Classic formats like lecture or laboratory exercises do not fulfill our requirements. Although, laboratory exercises fit the ILOs, the cost benefit ratio is poor, because they need expensive equipment and assistance by scientific and technical staff to operate the equipment.

However, the objective of high-quality scientific education does not necessarily go together with high-level scientific findings. Taking into consideration that the focus must be on learning how to work methodically, we scale-down the cost-intensive equipment of the classic laboratory exercise keeping up the methodical approach. Using experimentation kits by Fischertechnik instead (a classic educational toy in Germany) and having a qualified peer-tutor allows initiation of research-based learning processes, which cover the ILOs even at lower costs than the classical laboratory format.

\section{The Learning Activity}

Students get the task to write a scientific report that describes their experiment, including set-up, methods, materials, findings and conclusions. At the beginning of their studies, students get support in terms of instructions for the experimental set-up and a prepared hypothesis, which

they have to verify experimentally. They also get some questions that lead them through the research process. Students in higher semesters will be asked to find their own hypothesis as part of the FLExperiment.

While conducting the FLExperiment students will pass through the iterative learning process shown in fig. 3, starting with the hypothesis. Next, the first experiment will be executed. After this, students will need to create assumptions, which enables them to describe the experiment by mathematical and physical equations. This description will be verified during the next experiment. After several iterations and as many amended assumptions, students will write their scientific report and conclude on their findings.

The FLExperiment presented in this paper starts with the given hypothsis, which corresponds to (3.) Abstract Conzeptualisation in Kolb's terms. The following experiment corresponds to (4.) active experimentation.

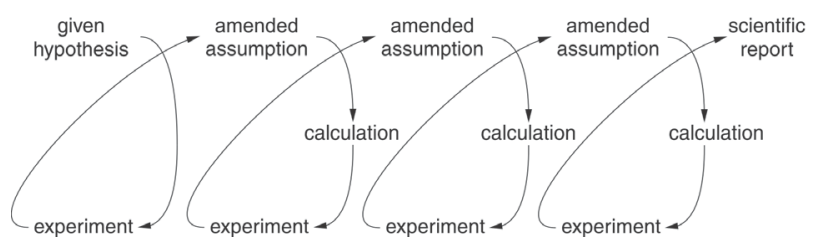

Figure 3. Iterative process

The first experiment aims at irritating students, corresponding with (1.) Concrete Experience. During the experiment, students reflectively observe (2.) the process. The observations give the first impulse to accept or amend assumtions corresponding to (3.) Abstract Conceptualisation. With the next experiment the cycle starts again.

As students repeatedly run through the learning cycle they synchroniously run through (parts of) the research cycle.

\section{Assement-Give Stundents Feedback}

In this state of development our new format is an extracurricular offering for students. Following Biggs' design concept Constructive Alignment assessment is an important part of the learning process. Instead of a strict examination, tutors review the scientific reports and give the students qualitative feedback. Once the FLExperiments are an integrated module of the curriculum, we would grade in how far the students have attained the ILOs.

\section{FLEXPERIMENT: LOOP}

In this section, as an example, we present the process and possible findings of a FLExperiment from the field of kinetics: the Loop. The experimental set-up is shown in fig. 4. A steel ball is positioned at a determined starting position. When released, it will roll down an inclined line and enter a loop. Depending on its starting height, it will complete the loop and roll to the outlet, or it will starve within the loop and fall down.

\section{A. The Challenge-Kick off}

If students want to make the FLExperiment Loop, we provide them the experimental set-up (fig. 4), the hypothesis that follow and two questions leading their research process.

Hypothesis: The behavior of the steel ball rolling through the loop differs from the mathematical description.

Two questions should help students to verify the hypothesis:

1. Which is the minimal starting position (height) that the steel ball with mass $m$ needs to run through the loop?

2. In how far does the mass of steel ball influence the movement?

These questions can be answered by using equipment, materials and methods as follows.

\section{B. Equipment, Materials, Methods}

Students get the materials, to build the experimental set-up (fig. 4). It is built from parts of a professional experimentation kit by Fischertechnik, a system that is widely used in education for modelling mechanical systems. The Loop 


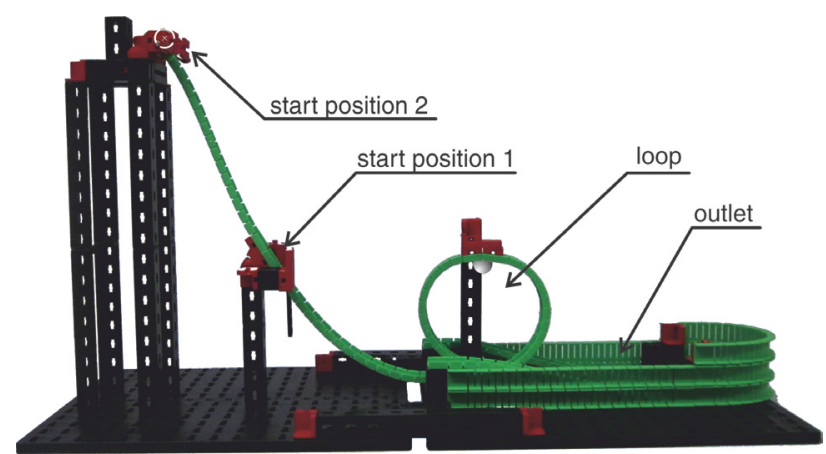

Figure 4. Experimental set-up

set-up has two starting positions. Additionally, a steel ball with the mass of 7 gram is provided.

\section{What Students Do}

To start with the FLExperiment, students will set-up the experiment according to the provided building instructions. They will approximately spend 30 minutes on this preparation. After this they can conduct the first experiment. Subsequently, they will need more information for the next steps.

It is then the students' task to search for the information needed in order to verify the hypothesis. In the course of this research phase they can use the local library to find books and other literature or use their lecture notes. In this FLExperiment we expect the students to find basic literature and consult their lecture notes in fields of technical mechanics, physics and mathematics.

\section{Findings}

Students go through the iterative process several times (fig. 3), following their knowledge from lectures, finding differences between calculation and the real movement, amending their assumptions and so forth.

1) First Round (simple conservation of energy)

In the first attempt, students would try to solve the problem assuming that the steel ball is a mass point, as they remember their Mechanics lectures. They would analyze the potential energy and the kinetic energy. Using the principle of conservation of energy students would determine the potential energy of the steel ball at starting position. They would also determine the potential energy of the steel ball at the height of the loop and calculate which kinetic energy is in the system at this time. To determine the kinetic energy, they would calculate the minimal velocity that the ball needs to roll through the loop on the track. The minimal velocity requires the centrifugal force [16].

$$
F_{z}=m \cdot a_{z}=m \cdot \frac{\omega^{2}}{r}=m \cdot \frac{\omega^{2} \cdot r^{2}}{r}=m \cdot \omega^{2} \cdot r
$$

This centrifugal force and weight (force) are set equal. The outcome of the new equation is the angular velocity, which gives the minimal tangential velocity.

$$
v_{\min }=\sqrt{g \cdot r}
$$

With the minimal velocity students would calculate the first minimal start position based on the conservation of energy.

$$
E_{p o t, 1}=E_{k i n, 2}+E_{p o t, 2}
$$

The experimental validation of the calculated value would fail, as the ball would not pass the loop but starve half way. Students would have to amend their assumption.

2) Second round (conservation of energy II)

Secondly, students would solve the problem assuming that the steel ball is a rigid body. Now, the energy, which results of the rotating steel ball, is to be analyzed, too.

$$
E_{\text {pot }, 1}=E_{\text {kin,trans }, 2}+E_{\text {kin,rot }, 2}+E_{\text {pot }, 2}
$$

To calculate the rotating energy the moment of inertia is needed [17].

$$
\mathrm{J}_{\overline{\mathrm{x}}}=\tilde{\mathrm{n}} \int_{\mathrm{V}} \mathrm{r}^{2} \mathrm{dV}
$$

There are two possible methods to calculate the moment of inertia. First Students could use the basic form by using integral calculus or second they could use a mechanical trades handbook. The resulting minimal starting positions slightly differ.

The new minimal starting position should then be verified by experimentation. During this experiment students will see that from the second starting position the ball will not complete the loop.

\section{3) Third round (friction between steel ball an track)}

Thirdly, students would try to rate the friction between steel ball and track. Then they could get a third minimal starting position.

$$
E_{p o t, 1}=E_{k i n, t r a n s, 2}+E_{k i n, r o t, 2}+E_{p o t, 2}+W_{f r i c}
$$

To rate the friction and find or develop an experimental method to check the findings is a typical work of engineers. After this final challenge students would structure and reflect upon their proceedings, and document their findings in a scientific report.

\section{CONCLUSION AND OUTLOOK}

This paper presents a research-based learning format for engineering education (work in progress) in a new learning environment. FLExperiments let students experience the process of solving technical problems already at the beginning of their engineering studies.

In the presented FLExperiment students conduct experiments to test and verify assumptions, to compare real movement with calculated behavior of a steel ball. They integrate their knowledge on Newton's Laws, equilibrium of forces, conservation of energy, moment of inertia and friction between solids to solve a simple real world problem. They apply their mathematical skills to calculate the moment of inertia by solving the integrals. Finally they communicate their research process and their findings in a scientific report.

In FLExperiments students perceive the Big Picture of engineering science in an inspiring and active learning environment. 


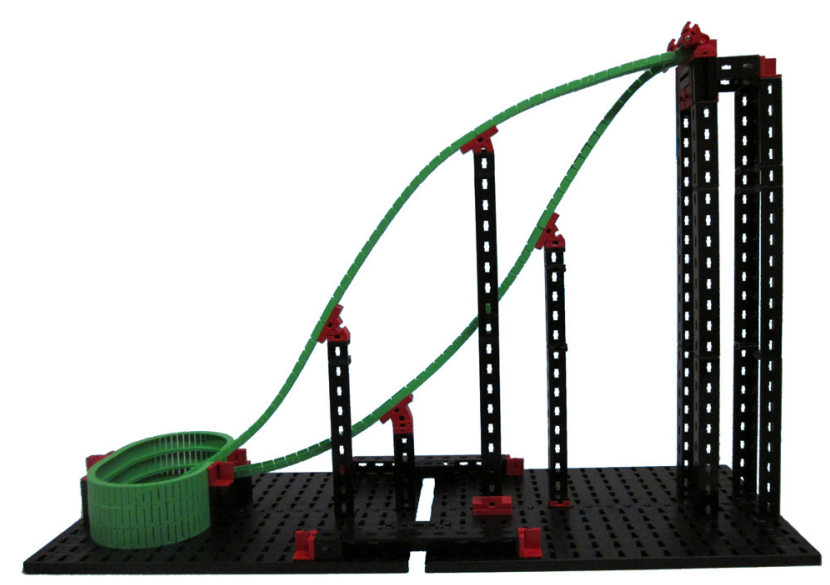

Figure 5. FLExperiment: Two Cycloids

The FLExperiment 'Loop' is the first experiment we developed for our learning format. Together with our tutors we continuously develop further FLExperiments, e.g. the 'Two cycloids' (c.f. fig. 5), in which students learn to mathematically argument why a steel ball is faster on the one track than on the other.

Besides the development of further experiments our work aims at integrating FLExperiments into the course syllabus respectively into the curricula of engineering programs. This would allow students to earn credit points for participation in our research workshop.

\section{REFERENCES}

[1] T. Jungmann, "Innovation und Kreativität durch Forschendes Lernen," ATZagenda, vol. 1, no. 1, pp. 114-118, 2012. http://dx.doi.org/10.1007/s40357-012-0005-8

[2] P. Ossenberg and T. Jungmann, "FLExperiment: Solving small technical problems by using mathematical and physical knowledge, skills and competencies in Engnineering Education," in Proceedings of the 2013 IEEE Global Engineering Education Conference (EDUCON), pp. 597-601.

[3] J. B. Biggs and C. Tang, Teaching for quality learning at university.: What the student does, 3rd ed. Maidenhead: McGraw-Hill, 2007.

[4] D. A. Kolb, Experiential learning: experience as the source of learning and development. Englewood Cliffs, NJ: Prentice Hall, 1984.

[5] T. Jungmann, "Forschendes Lernen im Logistikstudium: Systematische Entwicklung, Implementierung und empirische Evaluation eines hochschuldidaktischen Modells am Beispiel des Projektmanagements," Dissertation, TU Dortmund, Herne, 2011.

[6] J. Wildt, Funktionen und Anforderungen von Prüfungen unter den Bedingungen neuer Lehr-Lernformen. Available: http://www.hrkbolgna.de/bologna/de/download/dateien/Wildt Funktion Anforde rung Pruefungen.pdf (2011, Nov. 03).

[7] M. Abdulwahed and Z. K. Nagy, "Applying Kolb's Experiential Learning Cycle for Laboratory Education," Journal of Engineering Education, vol. 98, no. 3, pp. 283-294, http://www.jee.org/2009/july/7.pdf, 2009. http://dx.doi.org/10.10 02/j.2168-9830.2009.tb01025.x

[8] M. Arnegger, Begleittext zum Vortrag: Wie können soziale Kompetenzen vermittelt werden? Die Theorie des erfahrungsori- entierten Lernens von David A. Kolb. Tagung "Vielfalt in der Fortbildung" - 12.11.2010. Available: http://www.xenos-berlin. de/attachments/article/199/Handout dieWille.pdf (2011, Dec. 19).

[9] J. Wildt, "Guidelines for Educators: 'From the sage on the stage to the guide at the side'," Neues Handbuch Hochschullehre, pp. Griffmarke J 1.8, 2010.

[10] J. Wildt, "Forschendes Lernen: Lernen im 'Format' der Forschung," Journal Hochschuldidaktik, vol. 20, no. 2, pp. 4-7, http://www.hdz.tu-dortmund.de/fileadmin/JournalHD/2009 2/200 9 2_Wildt.pdf, 2009.

[11] N. Falchikov, Learning together: Peer tutoring in higher education. London: Routledge Falmer, 2005.

[12] D. Boud, "Introduction: making the move to peer learning," in Peer learning in higher education: Learning from \& with each other, D. Boud, R. Cohen, and J. Sampson, Eds, London: Kogan Page, 2001, pp. 1-17.

[13] J. Wallace, "Peer tutoring: A collaborative approach," in Opening Doors: Learning Support in Higher Education, S. Wolfendale and J. Corbett, Eds, London: Cassell, 1996.

[14] A. E. Mahdi, "Introducing peer-supported learning approach to tutoring in engineering and technology courses," International Journal of Electrical Engineering Education, vol. 43, no. 4, pp. 277-563, 2006. http://dx.doi.org/10.7227/IJEEE.43.4.1

[15] L. D. Feisel and A. J. Rosa, "The Role of the Laboratory in Undergraduate Engineering Education," Journal of Engineering Education, vol. 94, pp. 121-130, 2005. http://dx.doi.org/10.1002/ j.2168-9830.2005.tb00833.x

[16] P. A. Tipler, Physics: Volume 1, 2nd ed. New York, N.Y: Worth Publishers, 1982.

[17] D. Gross, J. Schröder, and W. A. Wall, Technische Mechanik: Band 3: Kinetik, 11th ed. Berlin, Heidelberg: Springer, 2010.

\section{AUTHORS}

P. Ossenberg co-ordinates the 'Research Workshop for Engineering Students' at TU Dortmund University, Dortmund, Germany (e-mail: philipp.ossenberg@tudortmund.de).

Prof. Dr.-Ing. T. Jungmann teaches Engineering Classes at FOM Hochschule, Essen. As Director of the FOM School of Engineering he develops and implements engineering study programs at FOM Hochschule. As a researcher at TU Dortmund University he manages the Research Workshop for Engineering Students. Jungmann has been researching Engineering Education since 2009. As a Trainer for Professional Teaching and Learning in Engineering Education he has founded the 'Institut für Ingenieurdidaktik', an institution that offers didactical training to lecturers and teaching staff as well as consulting to engineering departments at German universities. (email: thorsten.jungmann@fom.de)

The authors would like to thank the German Federal Ministry of Education and Research BMBF for funding the project ELLI - excellent learning and teaching in engineering education (2011-2016) and the DLR Project Management Agency (part of the German Aerospace Center) for the implementation and support. This article was modified from a presentation at the Educon 2013 Conference at Technische Universität Berlin, Berlin, Germany in March 2013. Manuscript received 15 May 2013. Published as resubmitted by the authors 21 May 2013. 